J. Clin. Chem. Clin. Biochem.

Vol. 28, 1990, pp. $863-872$

(C) 1990 Walter de Gruyter \& Co. Berlin $\cdot$ New York

\title{
Determination of Gangliosides in Human Cerebrospinal Fluid by High-Performance Thin-Layer Chromatography and Direct Densitometry
}

\author{
By Milica Trbojević-Čepe and Ivica Kračun \\ Institute of Clinical Laboratory Diagnostics, Zagreb University School of Medicine, Clinical Hospital Centre, \\ Zagreb, Yugoslavia
}

(Received January 4/July 16, 1990)

Summary: A method for the separation and quantification of a complex ganglioside mixture from a clinically available amount $(5 \mathrm{ml})$ of human cerebrospinal fluid (CSF) is described. After reduction of the CSF volume by ultrafiltration, gangliosides are extracted with methanol/chloroform, then separated and quantified by high performance thin layer chromatography (HPTLC) and direct densitometry. For purification of crude ganglioside extract, the method of choice was microdialysis against water. Recovery for the present method including all methodological steps was $78 \%$. No delective loss of gangliosides was demonstrated.

The CSF ganglioside pattern from 'normal' CSF samples resembles that of brain gangliosides, particularly cerebellum gangliosides. Based on chromatographic comparison with standards, the percentages of lipidbound NeuAc-positive fractions were:



The total ganglioside content varied between $616-944 \mu \mathrm{g} / \mathrm{l}$.

Within-run and between-run assay precision (relative standard deviation) for 'normal' pooled CSF ranged from 0.04 to 0.12 for the predominant CSF ganglioside fractions $\left(G_{D 1 a}, G_{D 1 b}, G_{T 1 b}, G_{Q 1 b}\right)$, and from 0.13 to 0.23 for the less pronounced fractions $\left(\mathrm{G}_{\mathrm{M} 1}, \mathrm{G}_{\mathrm{D} 3}\right)$.

\section{Introduction}

The content of lipids in cerebrospinal fluid (CSF) is very low (1). Gangliosides ${ }^{1}$ ) are sialic acid-containing glycosphingolipids displaying their highest concentrations in nervous tissue (2). Their accumulation in CSF in lipid storage diseases (gangliosidosis) has been dem-

1) See page 864 . onstrated (3). So far, only a few published studies have shown that the ganglioside profile of CSF more closely resembles that of brain tissue than that of plasma (4-6). However, due to methodological difficulties, the gangliosides in normal human CSF were not clearly identified in these previous reports. Quantification of gangliosides in the picomolar range using scanning densitometry on high-performance thin- 
layer chromatography (HPTLC) has been reported $(7,8)$. The aim of this study was to present a method suitable for simultaneous profile analysis and ganglioside quantification from clinically available amounts of CSF $(5 \mathrm{ml})$. The method consisted of ganglioside extraction, separation and quantification, employing HPTLC on silica gel and scanning densitometry.

\section{Materials and Methods}

All reagents were of reagent-grade quality. Solvents were redistilled before used. A commercially available apparatus from Sartorius GmbH (Göttingen, FRG) and collodium bags SM 13200 , were used for ultrafiltration. Sephadex G-25 fine was purchased from Pharmacia Fine Chemicals (Uppsala, Sweden). Standard dialysis membranes from Technicon Chemicals Co. (Orcq, Belgium) were used for dialysis. High-performance thinlayer chromatographic plates (HPTLC) silica gel $60(10 \times 10$ $\mathrm{cm}$ ) were purchased from Merck (Darmstadt, FRG). The Cronassial ganglioside mixture from Fidia (Abano Terme, Italy), diluted $1: 10$ with water $(0.5 \mathrm{~g}$ per litre of gangliosides) was used as a standard for the ganglioside HPTLC determination. Coronassial contains: $\mathrm{G}_{\mathrm{M} 1}(21 \%), \mathrm{G}_{\mathrm{D} 1 \mathrm{a}}(40 \%), \mathrm{G}_{\mathrm{D} 1 \mathrm{~b}}(16 \%)$ and $\mathrm{G}_{\mathrm{T} 1 \mathrm{~b}}(19 \%)$. Radiolabelled $\left[{ }^{3} \mathrm{H}\right] \mathrm{G}_{\mathrm{Dia}}(1 \mathrm{~g} / \mathrm{l})$ was a generous gift from Dr. G. Schwarzmann, Inst. Organ. Chem. Biochem., University of Bonn (14000 counts/min $\left.\cdot 5 \mu \mathrm{g} \mathrm{G}_{\mathrm{D} 1 \mathrm{a}}\right)$. $\mathrm{G}_{\mathrm{M} 2}$ ganglioside (bovine) was purchased from Calbiochem. A LKB 2202 Ultrascan Laser Densitometer and a 2220 Recording Integrator (Bromma, Sweden) were used for densitometric analysis.

Lumbar CSFs were obtained from adult patients and children with various neurological diseases. CSFs from adults free of any signs of acute inflammatory process of the CNS, tumours, demyelination, intracranial haemorrhage or congenital errors of lipid metabolism, were used as 'normals'. After cytological and biochemical examinations, CSF samples were centrifuged

1) Designation according to IUPAC-IUB Recommendations (20).

Ganglioside abbreviations follow the nomenclature system of L. Svennerholm (19):

\begin{tabular}{ll}
\hline Svennerholm (19)* & Lipid Document $(20)^{* *}$ \\
\hline $\mathrm{G}_{\mathrm{M} 3}$ & $\mathrm{II}^{3} \mathrm{NeuAc}-\mathrm{LacCer}$ \\
$\mathrm{G}_{\mathrm{M} 1}$ & $\mathrm{II}^{3} \mathrm{NeuAc}-\mathrm{GgOse}_{4} \mathrm{Cer}$ \\
$\mathrm{G}_{\mathrm{D} 1 \mathrm{a}}$ & $\mathrm{IV}^{3} \mathrm{NeuAc}, \mathrm{II}^{3} \mathrm{NeuAc}-\mathrm{GgOse}{ }_{4} \mathrm{Cer}$ \\
$\mathrm{G}_{\mathrm{D} 1 \mathrm{~b}}$ & $\mathrm{II}^{3}(\mathrm{NeuAc})_{2}-\mathrm{GgOse}{ }_{4} \mathrm{Cer}$ \\
$\mathrm{G}_{\mathrm{T} 1 \mathrm{~b}}$ & $\mathrm{IV}^{3} \mathrm{NeuAc}, \mathrm{II}^{3}(\mathrm{NeuAc})_{2}-\mathrm{GgOse}_{4} \mathrm{Cer}$ \\
$\mathrm{G}_{\mathrm{Q} 1 \mathrm{~b}}$ & $\mathrm{IV}^{3}(\mathrm{NeuAc})_{2} \mathrm{II}^{3}(\mathrm{NeuAc})_{2}-\mathrm{GgOse}_{4} \mathrm{Cer}$
\end{tabular}

* $\mathrm{G}=$ ganglioside; $\mathrm{M}=$ monosialo; $\mathrm{D}=$ disialo; $\mathrm{T}=$ trisialo. Arabic numerals indicate sequence of migration in thin-layer chromatograms (19).

** NeuAc $=N$-Acetylneuraminic acid; Lac = lactose; $\mathrm{GgOse}_{4}=$ gangliotetraose $=$

$\operatorname{Gal}(\beta 1-3)$ GalNAc $(\beta 1-4) \mathrm{Gal}(\beta 1-4) \mathrm{GlcCer} ; \quad$ Cer $=$ Ceramide.

The location of the NeuAc residue is indicated by a Roman numeral designating the position of the monosaccharide residue in the parent oligosaccharide (counting from the ceramide end) to which the NeuAc residue is attached, with an Arabic numeral superscript indicating the position within that residue to which the NeuAc is attached (20). before ganglioside extraction ( $2000 \mathrm{~g}, 10$ minutes). Pooled 'normal' CSFs were used for method evaluation and statistical analysis. Recovery was measured in two ways, i.e. either with CSF itself using a radiolabelled tracer $\left({ }^{3} \mathrm{H}\right] \mathrm{G}_{\mathrm{Dla}}, 5 \mu \mathrm{g} / 5 \mathrm{ml}$ $\mathrm{CSF}$ ), or by processing the Cronassial ganglioside mixture in $\mathrm{H}_{2} \mathrm{O}$ or artificial CSF $(7 \mu \mathrm{g} / 5 \mathrm{ml}$ CSF art.). Artificial CSF consisted of CSF ultrafiltrate $(5 \mathrm{ml})$ and serum $(20 \mu \mathrm{l})$. Assay precision was evaluated by analysing pooled CSF (or Cronassial added to artificial CSF) twelve times on the same day and on different days in a period of four mounths. Linearity of the relationship between densitometric responses (total area) and ganglioside content was determined by spotting increasing amounts of gangliosides from diluted Cronassial on HPTLC plates.

\section{Ultrafiltration (vacuum dialysis)}

Native CSF samples $(5 \mathrm{ml})$ were reduced to about $0.5 \mathrm{ml}$ by ultrafiltration against water, the semipermeable membrane rinsed with $0.250 \mathrm{ml}$ of $0.077 \mathrm{~mol} / \mathrm{l}$ saline and the volume of the CSF concentrate adjusted to $0.750 \mathrm{ml}$.

\section{CSF ganglioside extraction procedure}

Gangliosides were extracted from CSF by a slightly modified method of Svennerholm \& Fredman (9). In place of the water phase, a reduced volume of CSF (concentrate) was used. The ratio chloroform-methanol-CSF was $1: 2: 0.75$ by volume. Briefly, $2 \mathrm{ml}$ of methanol were added to $0.75 \mathrm{ml}$ of CSF concentrate; after mixing on a cyclomixer, $1 \mathrm{ml}$ of chloroform was added and mixed again. The gangliosides were separated from other lipids by phase partition, after the addition of $0.65 \mathrm{ml}$ of water. The two phases were separated by centrifugation $(15-20$ $\min , 3000 \mathrm{~g}$ ), and the upper phase was set aside. For secondphase partition of the lower phase, $0.380 \mathrm{ml}$ of methanol and $0.250 \mathrm{ml}$ of water were added. The two upper phases were combined and evaporated to dryness $\left(37^{\circ} \mathrm{C}\right)$.

\section{Alternative procedure for CSF ganglioside extrac} tion

Gangliosides were directly extracted from $6 \mathrm{ml}$ of native CSF, using a solvent ratio of chloroform-methanol-CSF of $8: 16: 6$ by volume. For phase partition, $5.2 \mathrm{ml}$ of water were added. After overnight separation in a glass funnel, the upper phase was set aside. For second-phase partition of the lower phase, $3 \mathrm{ml}$ of methanol and $2 \mathrm{ml}$ of water were added. The two upper phases were combined and evaporated to dryness $\left(37^{\circ} \mathrm{C}\right)$.

Purification of crude ganglioside extract by microdi alysis

Crude ganglioside extract was dissolved in a few microlitres of chloroform-methanol-water $(60: 30: 4.5$, by volume) and quantitatively transferred to a microcup $(0.1 \mathrm{ml})$ for dialysis. After evaporation of the solvent to dryness, the ganglioside residue was dissolved in $100 \mu \mathrm{l}$ of water and the microcup covered with a dialysis membrane. After dialysis against water for about four hours, the dialysis membrane was pierced with the plastic tip of a $100 \mu \mathrm{l}$ micropipette, and the ganglioside water extract quantitatively transferred to a conical tube and evaporated to dryness.

Alternative procedure for purification of crude ganglioside extract by gel filtration on Sephadex G-25. A modified method of Wells and Dittmer (10)

Crude ganglioside extract was dissolved in chloroform-methanol-water $(60: 30: 4.5$, by volume) and applied to a Sephadex G-25 column $(110 \times 5 \mathrm{~mm}, 1.4 \mathrm{ml}$ bed volume, resin mixed 
with the same solvent mixture). The gangliosides were eluted from the column with 6-7 $\mathrm{ml}$ of the same solvent mixture. The column was then eluted with about $1 \mathrm{ml}$ of the second solvent mixture of chloroform-methanol-water $(20: 20: 7.5$, by volume), and the combined eluates were evaporated to dryness.

High performance thin-layer chromatography (HPTLC)

Gangliosides were separated using the ascending "sandwich" HPTLC technique (11). Two plastic $1 \mathrm{~mm}$-thick strips were used as gaskets. Before use, HPTLC plates were pre-washed with chloroform-methanol ( $1: 1$, by volume) and activated at $110^{\circ} \mathrm{C}$ during $60 \mathrm{~min}$. The ganglioside extract was dissolved in a few microlitres of chloroform-methanol-water $(60: 30: 4.5$, by volume) and quantitatively transferred onto a HPTLC plate. The samples were applied as a line. After formation of a "sandwich" the following solvent system was used for chromatographic separation of gangliosides: chloroform-methanol$12 \mathrm{mmol} / 1 \mathrm{MgCl}_{2}$ in $\mathrm{H}_{2} \mathrm{O}-13.3 \mathrm{~mol} / 1 \mathrm{NH}_{3}(60: 40: 9: 0.5$, by volume). Chromatography was performed at $17-18^{\circ} \mathrm{C}$ using a freshly prepared solvent system. Development was stopped when the solvent front reached $1-1.5 \mathrm{~cm}$ from the upper edge of the plate. After drying the HPTLC plate, the same procedure was repeated with a fresh solvent mixture.

Densitometric scanning and quantification of CSF gangliosides

For densitometric quantification, three standards of 5,10 and $15 \mu \mathrm{l}$ of diluted Cronassial (corresponding to $2.5,5$ and $7.5 \mu \mathrm{g}$ of gangliosides, respectively) were spotted on the same HPTLC plate. Gangliosides were visualized on the plate (as lipid-bound $\mathrm{NeuAc}$ ) by spraying with resorcinol- $\mathrm{HCl}$ reagent diluted with an equal volume of water (12), and the HPTLC plate was heated as suggested by Ando et al. (13). Total amounts of CSF gangliosides were calculated from a calibration curve plotted from the densitometric response (total area) as a function of the amount of gangliosides $(\mu \mathrm{g})$ in standards (Cronassial). The content of individual ganglioside was calculated from the calibration curve based on an appropriate densitometric response (area) or from the relative percentage multiplied by the total content of gangliosides.

\section{Results and Discussion}

\section{Procedure of CSF ganglioside extraction}

Reduction of the CSF and solvent volumes increased the recovery and reproducibility of the extraction method (tab. 1). Ultrafiltration did not result in either any major loss of total gangliosides (tab. 1) or any selective loss (tab. 2), although the molecules involved were those of low molecular mass. The procedure is based on the assumption that CSF gangliosides are associated with proteins. Albumin is known to strongly bind to gangliosides (14). Moreover, a rapid procedure of CSF volume reduction causes an abrupt increase in ganglioside concentration, thereby triggering the formation of micelles of higher molecular mass (2).

Ultrafiltration also removes large quantities of salts (especially divalent cations) from the CSF before ex- traction of the gangliosides (CSF contains about 270 $\mathrm{mmol} / \mathrm{l}$ salts and $300 \mathrm{nmol} / \mathrm{l}$ gangliosides). A tendency of gangliosides to accumulate into a 'gangliosideprotein-divalent cation complex' at the interface in the biphasic solvent system has been described (15).

We also investigated whether this ganglioside isolation procedure, based on the partitioning method, is applicable in the present CNS pathology where less polar gangliosides (i.e. $\mathrm{G}_{\mathrm{M} 2}$ gangliosidosis) are elevated. About $75 \%$ of $\mathrm{G}_{\mathrm{M} 2}$ was recovered in the upper organic phase after adding $\mathrm{G}_{\mathrm{M} 2}$ ganglioside to a CSF sample (fig. 3e).

In pathological CSF samples with high protein concentrations, the concentration of polysialogangliosides, particularly $\mathrm{G}_{\mathrm{Q} 1 \mathrm{~b}}$, is decreased (tab. 3), but a similar effect was also demonstrated 'in vitro' by adding serum to CSF samples (tab. 3, fig. 1). A dramatic decrease in the concentration of polysialogangliosides $\left(\mathrm{G}_{\mathrm{Q} 1 \mathrm{~b}}\right.$ about $75 \%, \mathrm{G}_{\mathrm{T} 1 \mathrm{~b}}$ and $\mathrm{G}_{\mathrm{D} 1 \mathrm{~b}}$ about $50 \%$ ) was also observed after the addition of crude CSF ganglioside extract to serum, as determined by ganglioside extraction and HPTLC (figs. 3g, f). In contrast, a parallel experiment using isolated gangliosides of CSF and serum gave a strictly additive HPTLC analysis upon mixing (fig. 1). This means that high protein concentrations markedly interfere with the extraction of gangliosides. The action of serum sialidase as a possible cause of the decrease of ganglioside values was ruled out by replacing serum with pure albumin solution (fig. 1). Therefore, for the analysis of pathological CSFs with high protein concentration should be reduced less and the volume of organic solvents proportionally increased, allowing efficient protein precipitation and ganglioside extraction. The question remains, however, as to the nature of the real ganglioside pattern in serum or in other samples with high protein concentration.

\section{Purification of crude CSF ganglioside ex- tract}

Microdialysis is a very simple and reproducible method for crude CSF ganglioside extract purification, with good recovery $(98 \%)$ and no selective loss of gangliosides (tab. 1). In microdialysis, the CSF ganglioside extracts were dissolved in the least possible amount of water (up to $0.1 \mathrm{ml}$ ), thus achieving a ganglioside concentration closely approaching the critical micellar concentrations (2). Besides, the short time needed for dialysis (about 4 hours) also avoids any major loss of gangliosides. Such a brief dialysis is possible because the CSF samples are desalinated during the preceding procedure of ultrafiltration. 


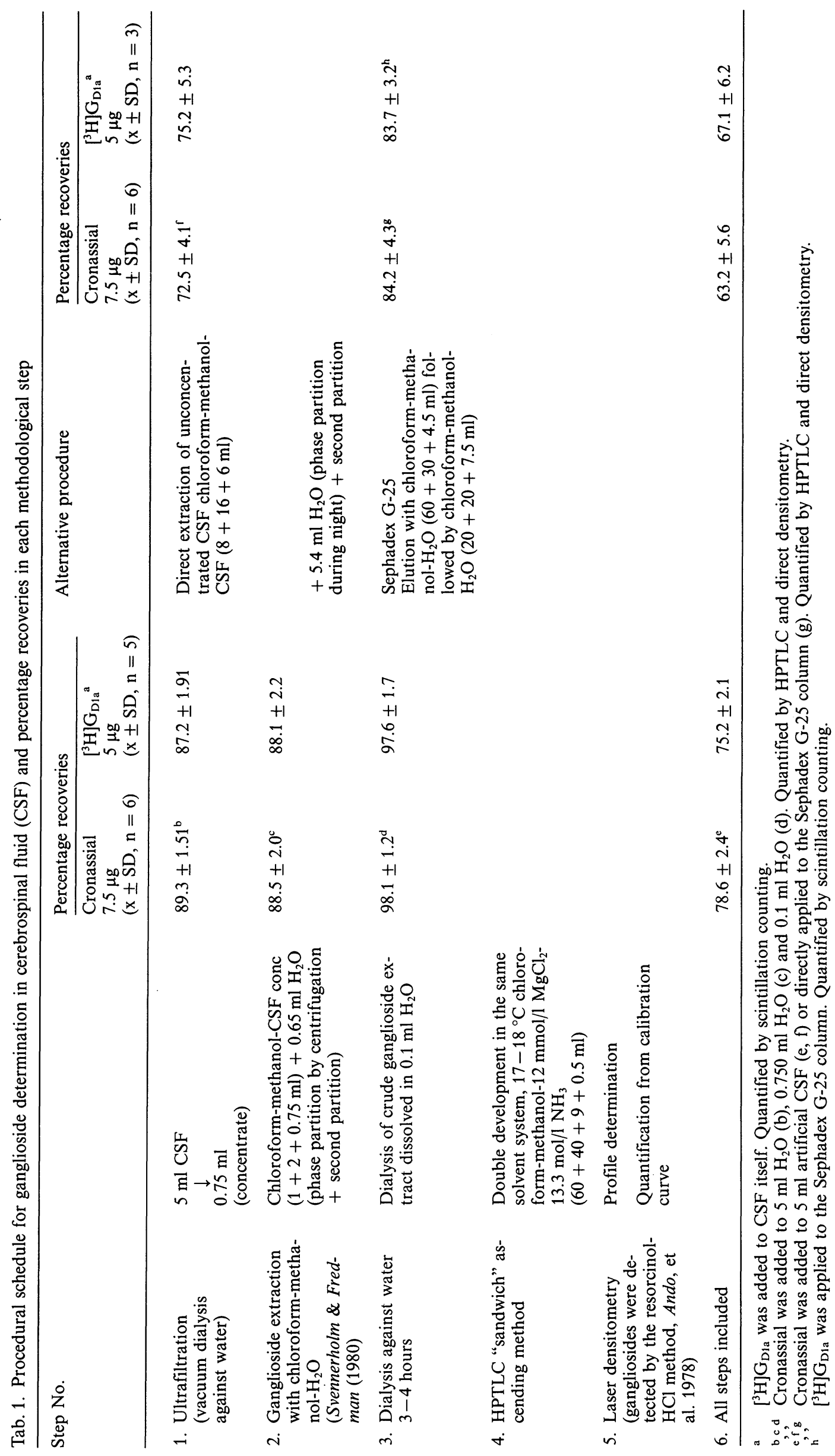


Tab. 2. Precision of ganglioside determination in cerebrospinal fluid (CSF)*

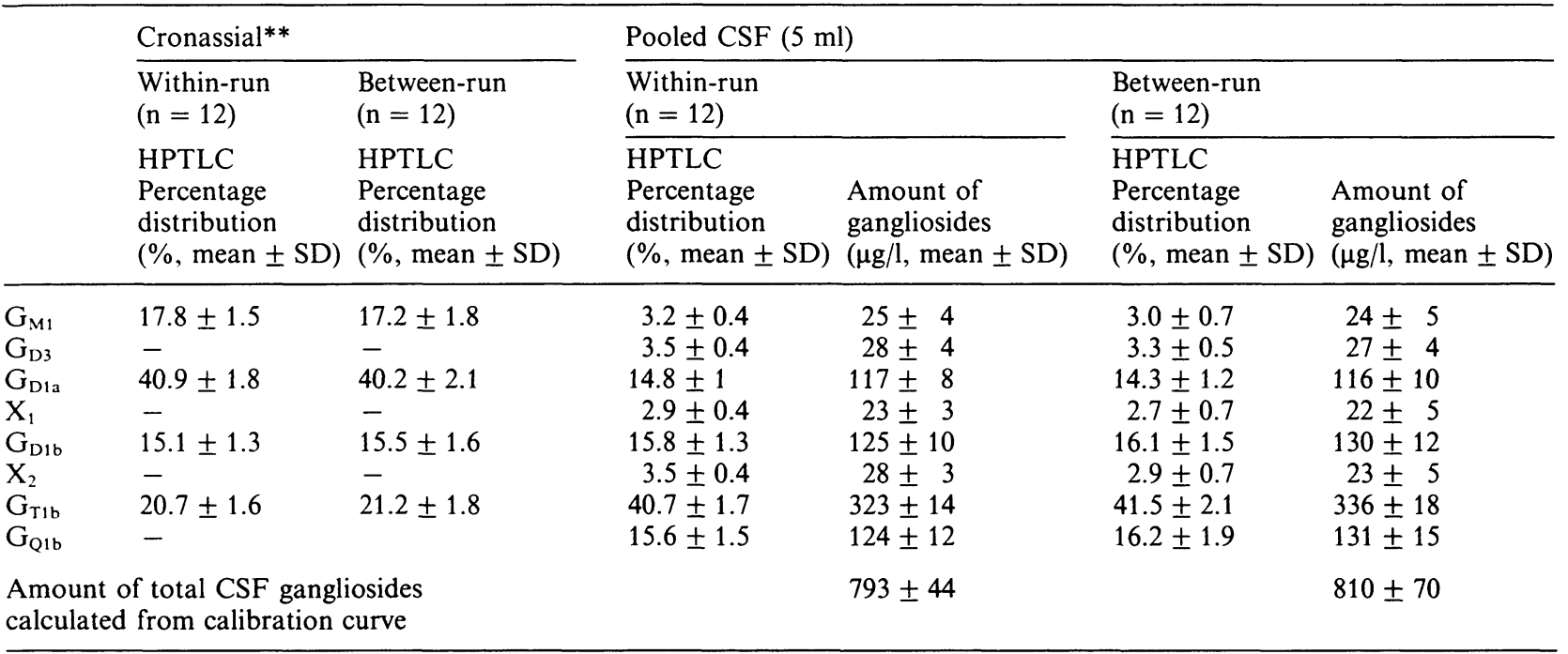

* All methodological steps are included (ultrafiltration, extraction, dialysis and HPTLC)

** Cronassial added to artificial CSF was used (see Material and Methods)

Purification of crude ganglioside extract by gel filtration on Sephadex G-25 columns is a methodologically more complex and less reproducible method (tab. 1). Use of the original procedure of Wells \& Dittmer (10) resulted in delay of trisialo- and tetrasialogangliosides on Sephadex G-25 (and the absence of $\mathrm{G}_{\mathrm{Q} 2 \mathrm{~b}}$ from the HPTLC-CSF ganglioside profile). Our modification of this method by changing the eluent polarity in the last milliliter results in the elution of $\mathrm{G}_{\mathrm{Q} 1 \mathrm{~b}}$ and $\mathrm{G}_{\mathrm{T} 1 \mathrm{~b}}$ gangliosides (fig. 2).

HPTLC and quantification by scanning densitometry

A high quality chromatogram is a prerequisite for ganglioside quantification by densitometry. Using the $\mathrm{HCl}$-resorcinol method for detection of lipid-bound $\mathrm{NeuAc}$, individual fractions containing about $60 \mathrm{ng}$ of ganglioside can be detected on HPTLC, if applied as a 6 -mm line (fig. 3).

Linearity of the relationship between the densitometric detector response (total area) and ganglioside content in standards (Cronassial) was demonstrated up to $10 \mu \mathrm{g}$ of gangliosides. A calibration curve for quantification of total CSF gangliosides was designed within this range.

Mullin et al. $(7,8)$ have reported that gangliosides after HPTLC and resorcinol staining produce different densitometric detector responses per mol of NeuAc (different calibration curves), due to differences in band geometry following migration. In our "sandwich" HPTLC technique, a lower chromatographic temperature $\left(17-18^{\circ} \mathrm{C}\right)$ without previous saturation of the TLC chamber with solvent vapour, and linear application of the sample resulted in ganglioside bands of nearly identical size and shape, thus minimizing the factors that might interfere when quantitating individual gangliosides within a mixture.

\section{Recovery and precision of CSF ganglioside determination}

Our results revealed an overall loss of about $25 \%$ of gangliosides during various methodological steps (tab. 1). No selective loss of gangliosides was demonstrated (tab. 2). Assay precision (relative standard deviation), within-run and between-run, ranged from 0.04 to 0.12 for major fractions $\left(G_{\mathrm{Q} 1 \mathrm{~b}}, \mathrm{G}_{\mathrm{T} 1 \mathrm{~b}}, \mathrm{G}_{\mathrm{D} 1 \mathrm{~b}}, \mathrm{G}_{\mathrm{D} 1 \mathrm{a}}\right)$, and from 0.13 to 0.23 for minor fractions $\left(G_{M 1}, G_{D 3}\right)$ (tab. 2).

\section{CSF ganglioside pattern (HPTLC)}

Lipid-bound NeuAc-positive fractions in 'normal' CSF samples were demonstrated in the following regions as defined by standards ( $\%$, mean): $\mathrm{G}_{\mathrm{M} 1}(3.4 \%)$, $\mathrm{G}_{\mathrm{D} 3}(3.6 \%), \mathrm{G}_{\mathrm{D} 1 \mathrm{a}}(14.6 \%), \mathrm{X}_{1}(2.5 \%), \mathrm{G}_{\mathrm{D} 1 \mathrm{~b}}(15.6 \%)$, $\mathrm{X}_{2}(3.8 \%), \mathrm{G}_{\mathrm{T} 1 \mathrm{~b}}(40.6 \%)$, and $\mathrm{G}_{\mathrm{Q} 1 \mathrm{~b}}(15.9 \%)$ (tab. 3).

The CSF ganglioside profile resembled that of brain gangliosides, particularly cerebellum gangliosides, with $\mathrm{G}_{\mathrm{T} 1 \mathrm{~b}}$ as a predominant fraction (16). Our results also showed $G_{D 1 a}$ to be higher in infancy (tab. 3), which correlated well with the results obtained on brain tissue (17). Higher proportions of $\mathrm{G}_{\mathrm{M} 3}$ and $\mathrm{G}_{\mathrm{D} 3}$ in pathological CSF ganglioside patterns correlated with the blood-brain barrier dysfunction (CSF haemorrhages, tumour processes), and suggested an increased transport of serum gangliosides into CSF. 


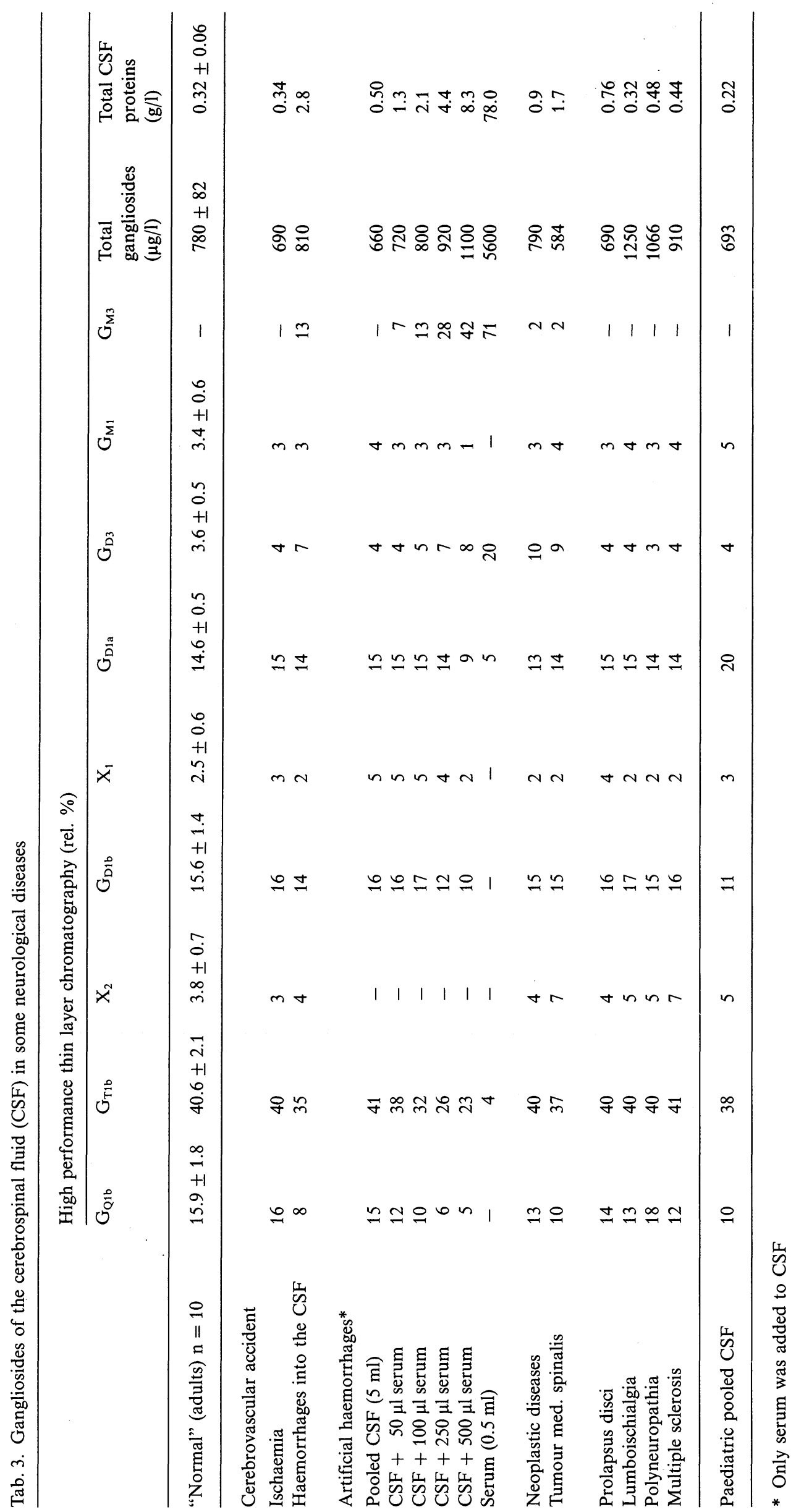




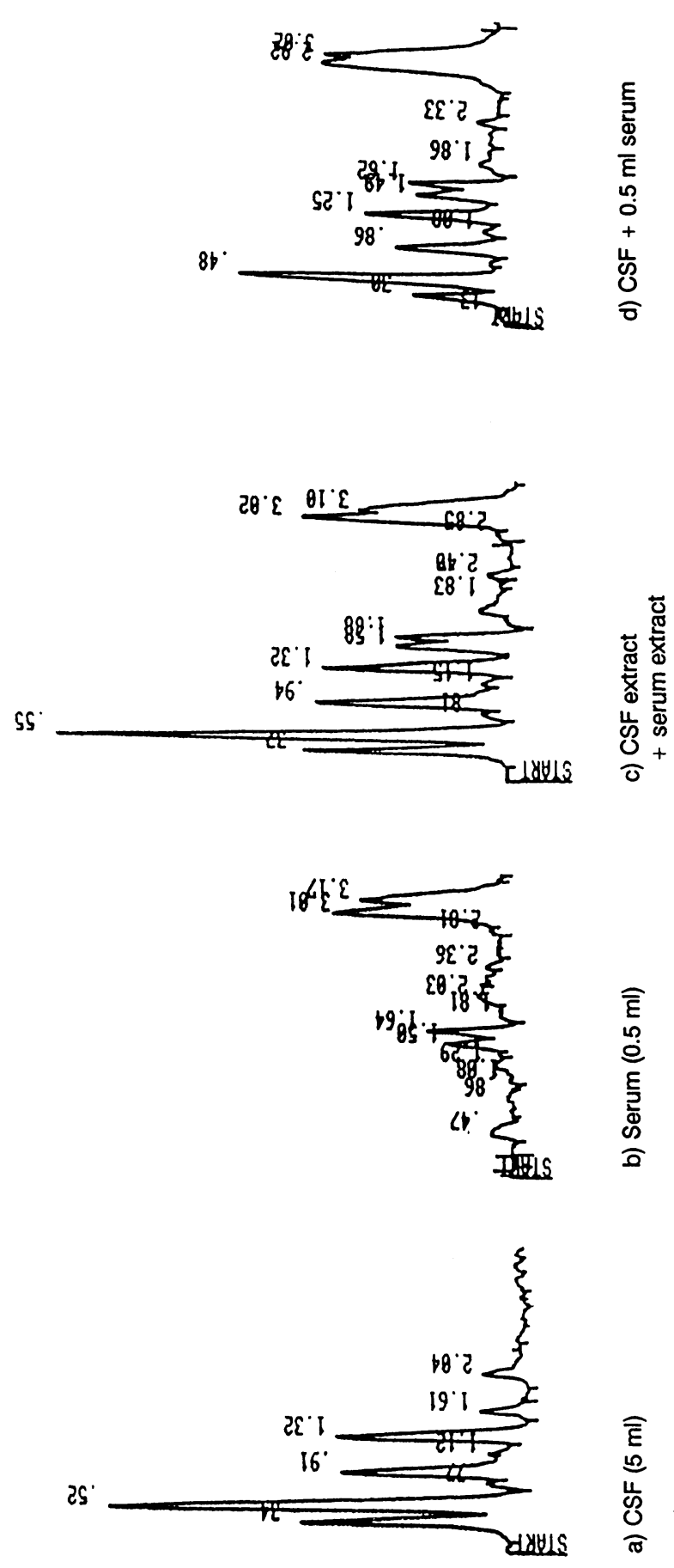




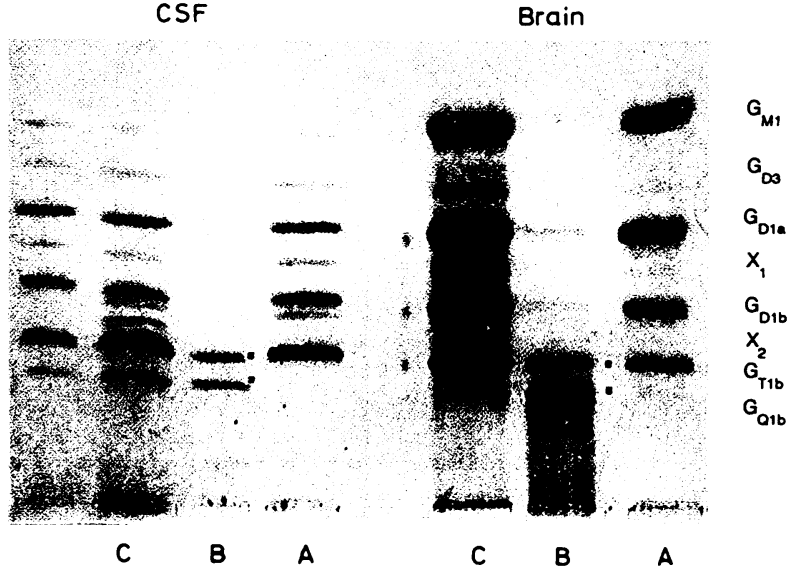

Fig. 2. HPTLC patterns of gangliosides from CSF and brain after purification of the crude ganglioside extract by the method of Wells \& Dittmer with Sephadex G-25 (A) and after our modification of this method (C) by changing effluent polarity in the last milliliter (B) (see Materials and Methods). Note a delay in the elution of trisialo- and tetrasialo-gangliosides on Sephadex G-25 columns when using the original method of Wells \& Dittmer. The ganglioside profile from CSF obtained by our modification did not differ from the profile produced by microdialysis (see fig. 2). Ganglioside fractions on HPTLC were visualized by spraying with resorcinol $/ \mathrm{HCl}$ reagent.

Bernheimer (4), Leeden \& Yu (5), and Nagai et al. (6) were the first to show that the TLC profile of CSF gangliosides is similar to that of the brain. Naturally, because of methodologic difficulties, these early chromatograms were of poor quality, or lacking certain fractions.

In contrast to these results, Hirabayashi et al. (18) have shown that $\mathrm{G}_{\mathrm{M} 1}$ and $\mathrm{G}_{\mathrm{D} 1 \mathrm{a}}$ gangliosides predominate in CSF, using a very sensitive method of enzymeimmunostaining on the TLC plate. The reason for the absence of the polysialogangliosides from the CSF profile, may have been an inadequate procedure of ganglioside extraction (chloroform/methanol alone, without aqueous phase), leading to the loss of polar gangliosides (9); or sialidase may have acted differentially on particular types of gangliosides and converted them into the corresponding asialolipids.

\section{Comparison of brain and CSF ganglioside patterns}

Parallel elution of the gangliosides of pooled "normal" CSF and of brain tissue from Sephadex G-25 columns showed almost identical compositions, not only of the major ganglioside fractions, but also of the fractions designated as $X_{1}, X_{2}$ and $X_{3}$. When a more polar solvent system for HPTLC was used, chloroformmethanol-12 mmol/1 $\mathrm{MgCl}_{2}$ in $\mathrm{H}_{2} \mathrm{O}-13.3 \mathrm{~mol} / 1 \mathrm{NH}_{3}$

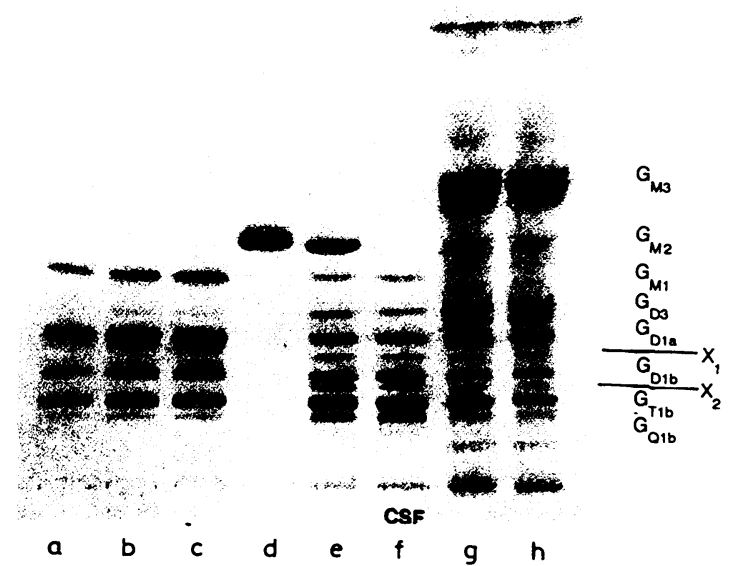

Fig. 3. HPTLC patterns of gangliosides from $5 \mathrm{ml} \mathrm{CSF} \mathrm{(f),}$ $5 \mathrm{ml} \mathrm{CSF}+5 \mu \mathrm{g} \mathrm{G_{M2 }}$ (e) and after addition of pure ganglioside extract from $5 \mathrm{ml} \mathrm{CSF}$ to $1 \mathrm{ml} \operatorname{serum}(\mathrm{g}, \mathrm{h})$. Note loss of polysialogangliosides after extraction of samples with high protein content. Crude ganglioside extracts were purified by microdialysis. Ganglioside fractions on HPTLC were visualized by spraying with resorcinol $/ \mathrm{HCl}$ reagent.

$\mathrm{a}, \mathrm{b}, \mathrm{c}, \mathrm{d}: 2.5,5$ and $7.5 \mu \mathrm{g}$ of Cronassial gangliosides, and $5 \mu \mathrm{g} \mathrm{G}_{\mathrm{M} 2}$ standard, respectively.

( $56: 44: 9: 0.5$, by volume), the fractions designated as $\mathrm{X}$ did not overlap with the major ganglioside fractions and migrated between $G_{D 1 a}$ and $G_{D 1 b}$ (fig. 4). Unidentified $X_{1}, X_{2}$ and $X_{3}$ could be detected in the composition of both brain and CSF gangliosides and probably corresponded to $\mathrm{G}_{\mathrm{T} 1 \mathrm{a}}\left(\mathrm{X}_{1}\right), \mathrm{G}_{\mathrm{D} 2}\left(\mathrm{X}_{2}\right)$ and $\mathrm{G}_{\mathrm{T} 3}\left(\mathrm{X}_{3}\right)$.

The data presented suggest that CSF contains gangliosides that are nearly identical with typical brain gangliosides. Therefore, CSF gangliosides are probably mostly secreted from brain cells, which appears to be supported by the appearance of $\mathrm{G}_{\mathrm{M} 2}$ ganglioside in the CSF of patients with $\mathrm{G}_{\mathrm{M} 2}$ gangliosidosis (3).

\section{Content of CSF gangliosides in 'normal' adults}

Our results on the total content of gangliosides in ten 'normal' CSFs, i.e. $780 \pm 82 \mu \mathrm{g} / 1$ of gangliosides (tab. 3), is comparable to that reported by Ledeen \& $Y u(466-1130 \mu \mathrm{g} / \mathrm{l})(5)$. The presence of contaminants (probably protein-bound NeuAc) might have been responsible for the higher ganglioside value in normal pooled CSF $(1320 \mu \mathrm{g} / \mathrm{l})$ reported by Nagai et al. (6). Our method eliminates this effect, as the ganglioside extract is first chromatographed on HPTLC, then lipid-bound NeuAc is determined by densitometry. 




Fig. 4. Comparison of brain (B) and normal CSF (A) ganglioside HPTLC patterns after parallel elution, millilitre by millilitre, from Sephadex G-25 columns (eluates from three columns were combined). Note almost identical profiles, not only of the major ganglioside fractions but also of those designated as $X_{1}, X_{2}$ and $X_{3}$, probably corresponding to $G_{T 1 a}, G_{D 2}$ and $\mathrm{G}_{\mathrm{T} 3}$. Ganglioside fractions on HPTLC were visualized by spraying with resorcinol/ $\mathrm{HCl}$ reagent.

* Change of effluent polarity in the final millilitre (see Material and Methods)

In contrast, Hirabayashi et al. (18) used an enzymeimmunostaining procedure to determine the concentration of total ganglio-series gangliosides in CSF and found it to be approximately $150 \mathrm{nmol} / \mathrm{l}$. The mean value of the ganglioside content in our study was 352 $\mathrm{nmol} / \mathrm{l}^{2}$ ), suggesting a loss of polysialogangliosides in the procedure of Hirabayashi et al.

$\left.{ }^{2}\right)\left\{\mathrm{G}_{\mathrm{M} 1}(16 \mathrm{nmol} / \mathrm{l}), \mathrm{G}_{\mathrm{D} 3}(15 \mathrm{nmol} / \mathrm{l}), \mathrm{G}_{\mathrm{D} 1 \mathrm{a}}(61 \mathrm{nmol} / \mathrm{l}), \mathrm{G}_{\mathrm{D} 1 \mathrm{~b}}\right.$ $(65 \mathrm{nmol} / \mathrm{l}), \mathrm{G}_{\mathrm{T} 1 \mathrm{~b}}(145 \mathrm{nmol} / \mathrm{l})$ and $\left.\mathrm{G}_{\mathrm{Q} 1 \mathrm{~b}}(50 \mathrm{nmol} / \mathrm{l})\right\}$, as calculated by using the appropriate molecular mass of each ganglioside.

\section{References}

1. Pilz, H. (1970) Die Lipide des normalen und pathologischen Liquor cerebrospinalis. Springer-Verlag, Berlin-Heidelberg - New York.

2. Wiegandt, H. (1985) Gangliosides, In Glycolipids (Wiegandt, H., ed.) pp. 199-260, Elsevier, Amsterdam-New York-Oxford.

3. Kotagal, S., Wenger, D. A., Alcala, H., Gomez, C. \& Horestein, S. (1986) AB variant $\mathrm{G}_{\mathrm{M} 2}$ gangliosidosis: Cerebrospinal fluid and neuropathological characteristics. Neurology $36,438-440$.

4. Bernheimer, H. (1969) Zur Kenntnis der Ganglioside im Liquor cerebrospinalis des Menschen. Klin. Wochenschr. $47,227-228$.

5. Ledeen, R. W. \& Yu, R. K. (1972) Gangliosides of CSF and plasma: Their relation to the nervous system. Adv. Exp. Med. Biol. 19, 77-93.
Our method can therefore be used for the follow-up and clinical evaluation of alterations in CSF gangliosides in various neurologic diseases.

\section{Acknowledgement}

Support offered by the Scientific Fund of Croatia, within the scope of the project entitled Biochemical and Immunochemical Studies of Multiple Sclerosis, No. 1.08.03.05.39., is greatly appreciated. The authors express their thanks also to Antonija Redovnikovic, B. A., for her skilful editorial work.
6. Nagai, Y., Kanfer, J. N. \& Tourtellotte, W. W. (1973) Preliminary observations of gangliosides of normal and multiple sclerosis cerebrospinal fluid. Neurology 23, 945948

7. Mullin, B. R., Poore, C. M. B. \& Rupp, B. H. (1984) Quantitation of gangliosides in the picomolar range. $\mathrm{J}$. Chromatogr. 305, 512-513.

8. Mullin, B. R., Poore, C. M. B. \& Rupp, B. H. (1984) Quantitation of gangliosides in the picomolar range. J. Chromatogr. 305, 512-513.

9. Svennerholm, L. \& Fredman, P. (1980) A procedure for the quantitative isolation of brain gangliosides. Biochim. Biophys. Acta 617, 97-109.

10. Wells, M. A. \& Dittmer, J. C. (1963) The use of Sephadex for the removal of non-lipid contaminant from lipid extract. Biochemistry 2, 1259-1263. 
11. Stahl, E. (1969) In: Thin-layer Chromatography (Stahl, E., ed.) pp. 52-85, Springer-Verlag, Berlin-Heidelberg-New York.

12. Svennerholm, L. (1957) Quantitative estimation of sialic acid. Biochim. Biophys. Acta 24, 604-611.

13. Ando, S., Chang, N. \& Yu, R. K. (1978) High performance thin-layer chromatography and densitometric determination of brain ganglioside composition of several species. Anal. Biochem. 89, 437-450.

14. Tomasi, M., Roda, L. G., Ausiello, C., D’Angelo, G., Venerando, B., Ghidoni, R., Sonnino, S. \& Tettamanti, G. (1980) Interaction of $G_{M 1}$ ganglioside with bovine serum albumin, formation and isolation of multiple complexes. Eur. J. Biochem. 111, 315-324.

15. Hayashi, K. \& Katagiri, A. (1974) Studies on the interaction between gangliosides, protein and divalent cations. Biochim. Biophys. Acta 337, 107-117.
16. Kracun, I., Rosner, H., Cosovic, C. \& Stavljenic, A. (1984) Topographical atlas of the gangliosides of the adult human brain. J. Neurochem. 43, 979-989.

17. Kracun, I., Rosner, H. \& Cosovic, C. (1986) In: Gangliosides and Neuronal Plasticity (Tettamanti, G., Ledeen, R. W., Sandhoff, K., Nagai, Y. \& Toffano, G., eds.) pp. 67-76, Fidia Research Series, Liviana Press-Springer Verlag, Padova-Berlin - Heidelberg - New York - Tokyo.

18. Hirabayashi, Y., Koketsu, K., Higashi, H., Suzuki, Y., Matsumoto, M., Sugimoto, M. \& Ogawa, T. (1986) Sensitive enzymeimmunostaining and densitometric determination of ganglioseries gangliosides on thin-layer plate: pmol detection of gangliosides in cerebrospinal fluid. Biochim. Biophys. Acta 876, 178-182.

19. Svennerholm, L. (1963) Chromatographic separation of human brain gangliosides. J. Neurochem. 10, 613-623.

20. IUPAC-IUB Commission on Biochemical Nomenclature (CBN) (1977) The Nomenclature of Lipids-Recommendations, 1976. Eur. J. Biochem. 79, 11-21.

Milica Trbojević, $\mathrm{PhD}$

Institute of Clinical Laboratory Diagnostics

Zagreb University School of Medicine

Clinical Hospital Centre

Kispaticeva 12

YU-41000 Zagreb 